HARRAN ÜNIVERSITESI

MÜHENDISLIK DERGisi

HARRAN UNIVERSITY JOURNAL OF ENGINEERING

e-ISSN: 2528-8733

\section{HARRAN ÜNIVERSITTESI MÜHENDİSLİK DERGİSİ}

HARRAN UNIVERSITY JOURNAL of ENGINEERING

e-ISSN: 2528-8733 (ONLINE)

URL: http://dergipark.gov.tr/humder

Design and Implementation of an Experiment Device for Free Fall Experiment with Mobile Control Application

Serbest Düşüs Deneyi İçin Bir Deney Cihazı ve Mobil Kontrol Uygulamasının Tasarımı ve Gerçeklenmesi

Yazar(lar) (Author(s)): Ali Bahadır AYDEMIR' ${ }^{1}$, Ilyas CSANKAYA ${ }^{2}$

${ }^{1}$ ORCID ID: 0000-0002-6991-9328

${ }^{2}$ ORCID ID: 0000-0002-6072-3097

Bu makaleye şu şekilde atıfta bulunabilirsiniz (To cite to this article): Aydemir, A. B., Çankaya, İ., "Design and Implementation of an Experiment Device for Free Fall Experiment with Mobile Control Application", Harran Üniversitesi Mühendislik Dergisi, 6(3): 141-149, (2021).

Erişim linki (To link to this article): http://dergipark.gov.tr/humder/archive 


Mühendislik Dergisi

Araştırma Makalesi

\title{
Design and Implementation of an Experiment Device for Free Fall Experiment with Mobile Control Application
}

\author{
Ali Bahadır AYDEMİR ${ }^{1, *}$, İlyas ÇANKAYA ${ }^{2}$ \\ ${ }^{1}$ Atılım University, Engineering Faculty, Mechatronics Engineering Department, 06830, Incek Gölbaşı/ANKARA \\ ${ }^{2}$ Ankara Ylldırım Beyazıt University, Engineering Faculty, Electrical-Electronics Engineering Department, 06010, Etlik Keçiören/ANKARA
}

\begin{abstract}
Makale Bilgisi

Bassvuru: $21 / 12 / 2020$

Yayin: $30 / 12 / 2021$
\end{abstract}

Keywords

Free fall

Mobile control with

Bluetooth

Experiment device

Physics

Anahtar Kelimeler

Serbest düşüs

Bluetooth ile mobil kontrol

Deney cihazl

Fizik

\section{INTRODUCTION}

Free fall is an important topic in physics. It obtains valuable information about gravity, gravitational acceleration, potential to kinetic energy conversion, mass and air friction. It has valuable benefits for students in theoretical applications. However, real life experiments also provide valuable contributions in terms of seeing pre-calculated scenarios in real life and differences between theory and practice due to some ignored factors such as gravitational acceleration changes caused by altitude and air friction coefficient changes caused by air density differences. Inquiry and experiment based education increases academic achievement on learning [1,2]. There are some works related to make virtual free fall experiments [3], however it is not always possible to see all of real life disturbances on virtual experiments as parameters and there are some works suggesting that real life experiments contribute students more than virtual experiments [4]. Furthermore, there is also a research which shows students prefer experiments with real physical components [5]. The aim of the developed experiment device is to make students able to experience free-fall topics in real-life experiments in order to improve their understanding. 
An experiment device for free fall in order to measure fall time is developed and implemented in this study. Device uses a steel ball as drop object and an electromagnet to take, hold or release this ball. All actions are controlled by developed Android application, in which measurements and experiment results are showed and examined. Furthermore, an ordering algorithm is implemented on this application and device firmware in order to give working turns to students/groups and restrict them from interrupting each other's work or taking each other's turns.

Experimentation is an important topic for education, therefore a lot of work conducted on this area. There are some experiment setups for a variety of areas which are using computer interface with wired connection or via internet such as control [6,12], electrical machines and signal processing [13][14][15], power electronics and generators [16] and microcontrollers [17,18]. There are also some developed experiment setups with the purpose of free-fall experimentation which are controlled by a computer with wired connection $[19,21]$ and a study which uses smartphone as drop object to measure drop time [22]. However, this study do not propose an exact setup and other experimentation setup studies related to free-fall experiment are controlled with computer connection and interface. Developed free-fall experiment setup and Android control application has some novel features. One of these features is ability to control setup with a smartphone or tablet via Bluetooth connection to make experiments and gather data without the requirement of computer setup or wire connection. Internet infrastructure and connection is also not required for the usage of the setup and this ability differs from online controlled experiment setups. Other novel feature is developed algorithm within Android application which allows multiple groups to study on only one device with their smartphones or tablets with their group ID and gather data of their experiments without interrupting an another group's turn.

Developed device and Android application may contribute to the understanding of theoretical concepts about free fall by experimentation. Students can make different experiments and understand theoretical concepts better and see differences between theory and practical scenarios. Developed Android application with Bluetooth connection makes it easier to control the device and gather results due to wireless operation. Furthermore, device can be used without computer or computer setup, therefore it can be used in almost every type of environment easily without any setup other than an electricity plug. Another advantage of the developed system is that student groups can use the device with the ID algorithm of the application using their smartphones or tablets, therefore groups may conduct their experiments easily with only one device without computer. In general, experiment device and Android application may contribute education in terms of experimentation, easiness and multiple options of use with less equipment or preparation. These properties and advantages about educational usage also applies at the use for research purposes.

Developed device can be used in several experiment scenarios. Objects with different masses and shapes can be used in order to understand the effect of mass and shape in free-fall. Experiments can be conducted in different heights to see effect of changes in gravitational acceleration. If there is possibility, device can be operated at a vacuumed area to see effect of air friction in free fall.

Some experimentations are made using device and mobile application and these results showed. Furthermore, these results are compared with pre-calculated values and some differences examined.

\section{MATERIAL AND METHOD}

Experiment device and mobile control application is implemented, therefore some experiments have been made to test the device and obtain results to compare with theoretical calculations. These experiments were conducted for different heights which start with a minimum of 100 millimeters, end at a maximum of 1300 millimeters and increment with 100 millimeters steps, fall time is measured and three measurements were made for each height. During experiments, some parameters were not measurable due to the limitations of the study, therefore some assumptions were made.

Due to the altitude of the exact place of experiments with respect to the sea level was unknown and there was no ability to measure it, average height of district was used in the calculations of gravitational acceleration of earth. Furthermore, since air density of the laboratory at which experiments were conducted was unknown, a standart value for the air density was used. 
A steel ball with diameter of 20 millimeters and weight of 28 grams is used as falling object. All experiments made using device and mobile control application such as a student or researcher would use the device.

Measurements are made using "Auto Pick and Drop" feature of the mobile application which is detaily explained at Android application section.

Material and method for the development, implementation and test of the device is explained more detaily in experiment device and android applicataion sections. Experiment device section explains mechanical design, components and electronics used in the device while android application section explains graphical user interface of mobile control application and features of it.

\section{GENERAL INFORMATION ABOUT FREE FALL}

Free fall is the general name for falling motion of objects due to gravity. In free fall, object falls with gravitational acceleration and no other forces apply on it except air friction. There may be some initial angle or initial velocity of object during start of the motion. Developed experiment device interested in free fall of a steel ball which has no initial angle or velocity at the beginning of fall. In general, free fall with air friction and drag force caused by it is expressed with below formula derived from Newton's second law $[23]$

$$
m \frac{d v}{d t}=m g-\frac{1}{2} p C_{\mathrm{D}} A v^{2}
$$

Where $m$ is mass of the steal ball, $v$ is the fall speed, $\frac{d v}{d t}$ is the first derivative of the fall speed, $g$ is gravitational acceleration, $p$ is the density of the air, $A$ is cross-sectional area of the object and $C_{\mathrm{D}}$ is the dimensionless drag coefficient related to the shape of the falling body. In this study, $m$ is $0.028 \mathrm{~kg}, C_{\mathrm{D}}$ is $0.5, A$ is $0.000314 \mathrm{~m}^{2}$ since the steel ball has a diameter of $20 \mathrm{~mm}, p$ is considered as $1.225 \mathrm{~kg} / \mathrm{m}^{3}$ which is a standard value for a closed environment at a temperature of $15^{\circ} \mathrm{C}$. Gravitational acceleration $(g)$ changes with the altitude. Value of $g$ at sea level is $9.80665 \mathrm{~m} / \mathrm{s}^{2}$, and at different altitudes $g$ is calculated with below formula [23];

$$
g_{\text {(altitude) }}=g\left(\frac{r_{e}}{r_{e}+h}\right)^{2}
$$

Where $g_{(\text {altitude) }}$ is the gravitational acceleration at a specific altitude, $g$ is the gravitational acceleration at sea level, $r_{e}$ is the mean radius of the Earth and $h$ is the altitude in meters. Experiments were made at İncek district in Ankara/Turkey, which has a mean altitude of 1229 meters. Using these parameters, $g_{(\text {altitude) }}$ is calculated as $9.80287 \mathrm{~m} / \mathrm{s}^{2}$. These parameters and equations are used to calculate theoretical fall time values presented at the experimentation section.

\section{EXPERIMENT DEVICE}

Frame of the free fall experiment device is built with aluminum profiles in a rectangular form with 1630 $\mathrm{mm}$ height, $360 \mathrm{~mm}$ width and $360 \mathrm{~mm}$ depth. Aluminum plate profiles are used as bottom and roof platforms and aluminum profiles and other parts are connected to these plates. A ball screw is used to generate linear motion and two chrome shafts are used to support the motion. A plate is designed and manufactured with 3D printer to hold the electromagnet, two linear bearings for chrome shafts and ball screw nut. Screw pitch of the ball screw is $4 \mathrm{~mm}$, which means one complete rotation of ball screw changes linear position of the plate $4 \mathrm{~mm}$ in a direction. Motion is provided by a NEMA 23 type stepper motor. Maximum drop length is implemented as $1300 \mathrm{~mm}$ in the firmware, which is very close to the physical constraints of the mechanism. A bowl-like part is designed and manufactured with 3D printer in order to hold the ball when it dropped by the electromagnet. 


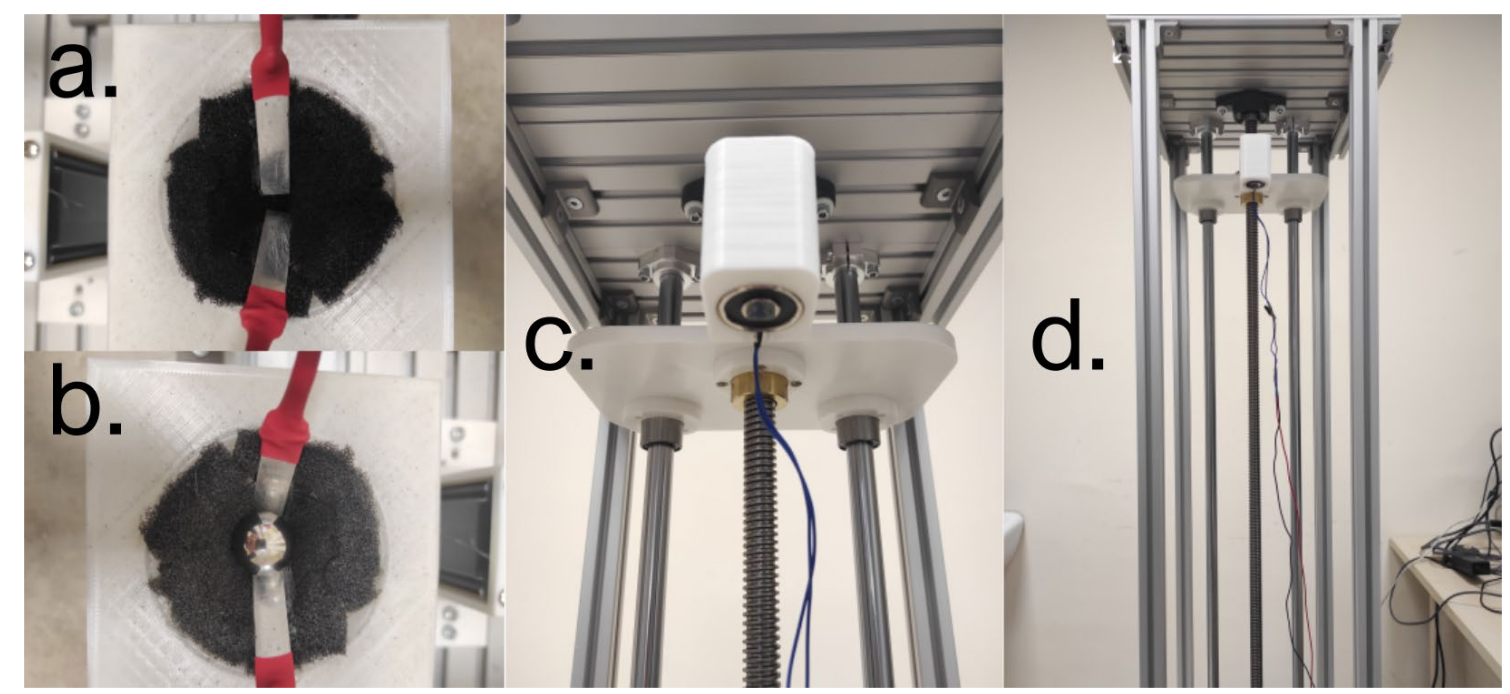

Figure 1. Pictures of the Device, Electromagnet and Bowl

In above pictures, a. is dropping bowl and b. is dropping bowl with steel ball, $\mathbf{c}$. is carrying head with electromagnet and $\mathbf{d}$. is a general picture of the device.

Electronics and power components of the device collected in a separate grounded electronics box for safety reasons. System is powered by a 12 Volts power supply which is connected to 220 Volts power inlet. A4988 stepper motor driver is used to drive step motor. An Arduino UNO board with ATMEGA328P-PU microcontroller is used as embedded controller and a HC-05 Bluetooth module is used for the communication with Android mobile device. There is also a MOSFET in electronics box used for opening and closing 12 Volts electromagnet. This MOSFET has an opening and closing time in terms of nanoseconds, therefore it's operation time is small enough to be ignored. There is a mechanical end switch in the device which makes it possible to home the carrying plate. There are two metal parts in the bowl. When the ball drops, it connects these two metal parts and they act like a pressed button. This makes the device able to understand the dropping moment of the ball. Pictures of the used electronic components shown below;

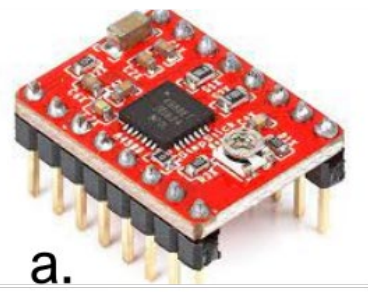

a.

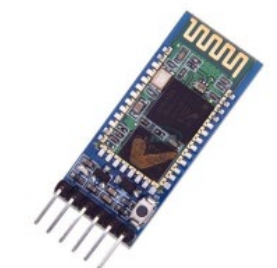

C.

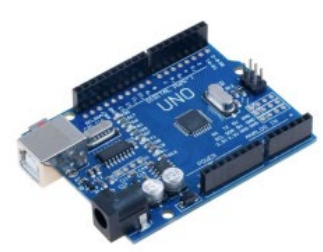

b.

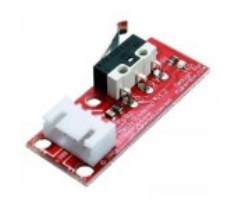

d.

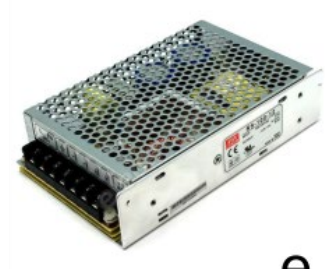

e.

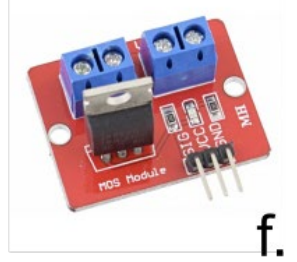

Figure 2. Pictures of used electronics components

In figure above, a. is the A4988 step motor driver, b. is the Arduino UNO microcontroller board, c. is the HC-05 Bluetooth communication module, $\mathbf{d}$. is the mechanical end switch, e. is the 12 Volts power supply and $\mathbf{f}$. is the MOSFET module. 
Arduino UNO board is programmed using $\mathrm{C}++$ language and Arduino IDE programming environment. A4988 step motor driver, mechanical end switch and MOSFET module is controlled by Arduino UNO. Motor voltage and electromagnet voltage is supplied by voltage supply to A4988 and MOSFET module as 12 Volts. MOSFET module opens and closes the electromagnet depending on received signal from Arduino UNO. Furthermore, one of the two plates which are connected when the ball drop is connected to ground and other one is connected to Arduino UNO pin which is in pull-up state. Therefore, Arduino UNO and developed embedded firmware can detect the drop of the ball.

Experiment device controlled only by Android application. When a motion input has received such as move the plate $10 \mathrm{~mm}$ up, device performs desired action and sends a message to the application about performed action. When a dropping input is received, device goes to homing position which is also the position to take the ball from the bowl, goes up to desired height and drops the ball. When the ball is dropped to the bowl, device measures drop time and sends it to the application. If multiple drop request is received by the experiment setup, this process is repeated. Each measurement is sent to the application as a different result. An operational diagram of the device is shown below;

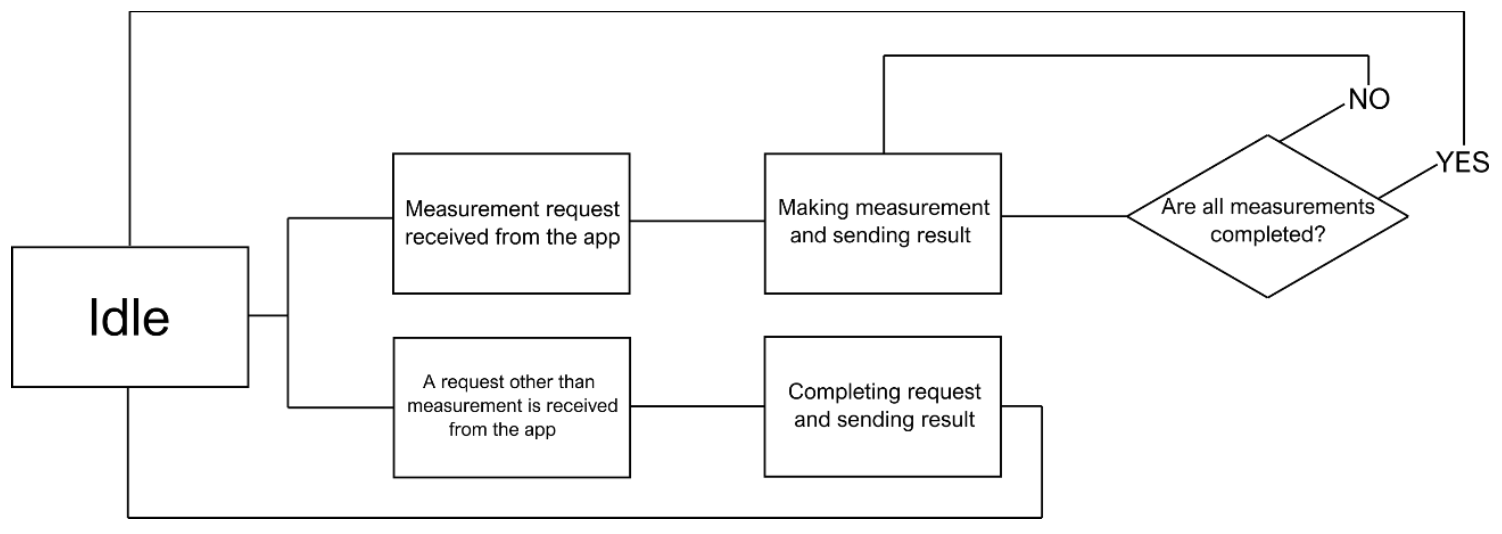

Figure 3. Operational diagram of the device

Measurements and experiments of a user is considered as completed if this user click "Disconnect \& End" button. Until this button is clicked, turn belongs to that user and any unwanted or accidental disconnections do not change turn order.

\section{ANDROID APPLICATION}

Android application is developed using MIT App Inventor platform. MIT App Inventor is a mobile development platform which uses graphical coding interface. Application has manual and automatic control options for different functions. Some screenshots shown below;
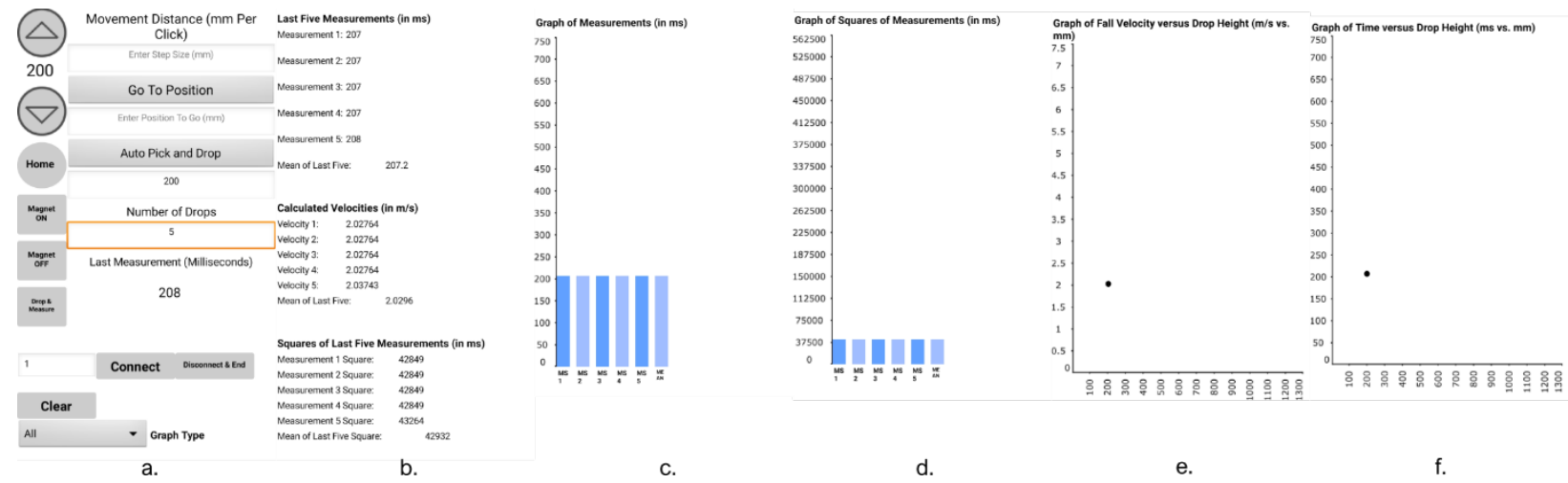

Figure 4. Graphical Interface of the Mobile Control Application

In picture a., all control buttons can be seen. At this screen, Arrow buttons move the head up and down with value entered in the movement distance part. Between arrow buttons, current position of the carrying head is displayed. "Home" button homes the device to the position at which it picks the ball with 
electromagnet. Home position is considered as zero and when homing is made current position is displayed as zero. "Magnet ON" and "Magnet OFF" buttons manually open and close the electromagnet. "Drop \& Measure" button closes the magnet and makes a measurement from current position of the carrying head. This enables user to make faster measurements if all measurements will be made from same height. "Go to position" moves the head to desired position. "Auto Pick and Drop" button homes the head, takes the ball, drops it from desired height and measures the dropping time. These dropping sequences are repeated number of times entered by the user in "Number of Drops" part. Also, type of resultant graphs can be selected from "Graph Type" selection.

Last five measurements, mean of last five measurements, squares of last five measurements, mean of squares of last five measurements and calculated velocities listed in screen $\mathbf{b}$. These values also shown as graphs which can be seen at screens c. and d. Furthermore, graph of velocity versus drop height can be seen at screen e. and graph of fall time versus drop height can be seen at screen $\mathbf{f}$. Since device does not have capability to physically measure drop velocity, velocity values are calculated partly theoretically using measured fall time values.

Connecting to the device requires a user id input. This input is entered by the user to the "User ID" part. These id's are arranged as 1,2 and 3 for the moment but it can be arranged inside the firmware easily to use an another type of id such as name or student number. When first user with id 1 connects to the device, make experiments and pushes "Disconnect \& End" button, device starts to wait for the connection of second user with id 2. If an another user with an id different than id 2 tries to connect to the device, for example if user with id 1 or 3 tries to connect, application shows an "It is not your turn for experiment!" error and disconnects user. Therefore, users or groups can work on one device with correct order without taking each other's turns. An operational diagram of this connection process is shown below;

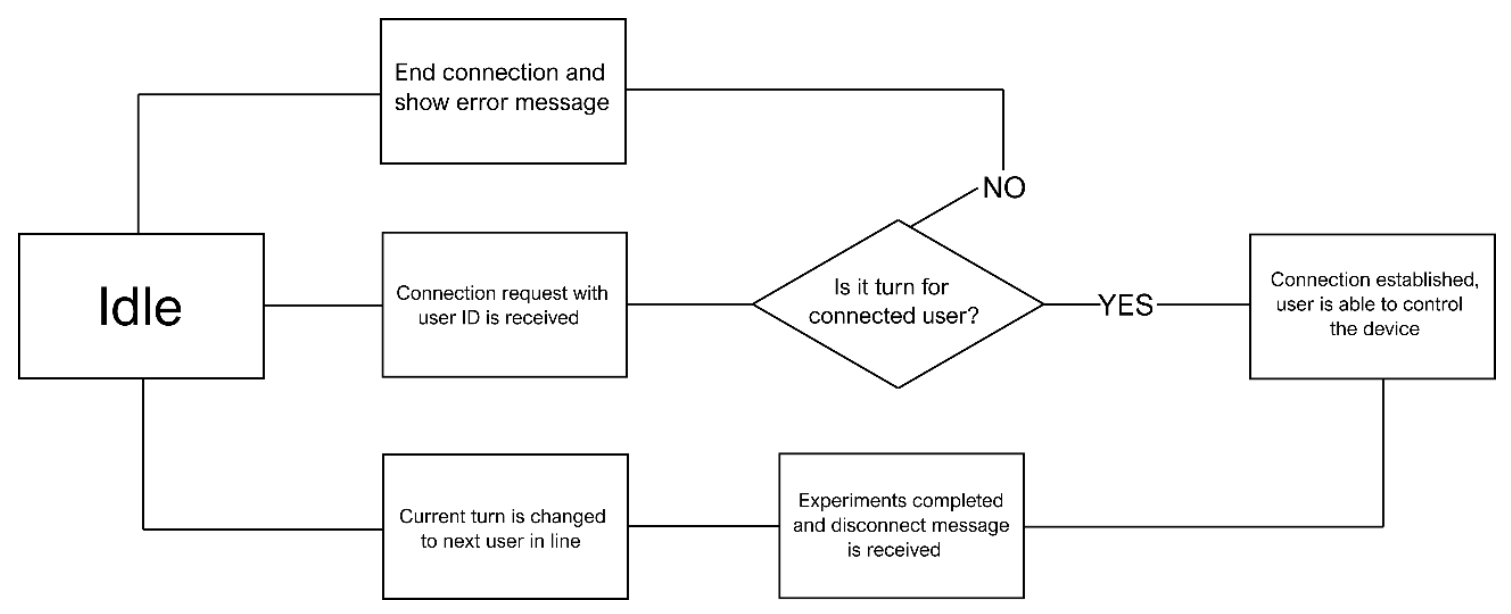

Figure 5. Operational diagram for the Android application connection via Bluetooth

\section{RESULTS AND DISCUSSION}

Experiments have been conducted with the device for a minimum 100 millimeters and a maximum of 1300 millimeters of drop height in a closed environment. Three measurements have been made for each height in units of milliseconds and these measurements, mean of these measurements, theoretically calculated fall time for related height and comparison of experimental and theoretical values are shared below.

Table 1. Experimental measurements, theoretical calculations and comparison for different heights

\begin{tabular}{lllllll}
\hline Height & $\mathbf{1}^{\text {st }}$ Measurement & $\mathbf{2}^{\text {nd }}$ Measurement & $\mathbf{3}^{\text {rd }}$ Measurement & Mean & $\begin{array}{c}\text { Theoretical } \\
\text { Value }\end{array}$ & Error \\
\hline $\mathbf{1 0 0} \mathbf{~ m m}$ & $148 \mathrm{~ms}$ & $149 \mathrm{~ms}$ & $148 \mathrm{~ms}$ & $148.33 \mathrm{~ms}$ & $142.84 \mathrm{~ms}$ & $5.49 \mathrm{~ms}$ \\
\hline $\mathbf{2 0 0} \mathbf{~ m m}$ & $207 \mathrm{~ms}$ & $207 \mathrm{~ms}$ & $208 \mathrm{~ms}$ & $207.33 \mathrm{~ms}$ & $202.02 \mathrm{~ms}$ & $5.31 \mathrm{~ms}$ \\
\hline $\mathbf{3 0 0} \mathbf{~ m m}$ & $253 \mathrm{~ms}$ & $254 \mathrm{~ms}$ & $254 \mathrm{~ms}$ & $253.67 \mathrm{~ms}$ & $247.44 \mathrm{~ms}$ & $6.23 \mathrm{~ms}$ \\
\hline $\mathbf{4 0 0} \mathbf{~ m m}$ & $292 \mathrm{~ms}$ & $292 \mathrm{~ms}$ & $292 \mathrm{~ms}$ & $292.00 \mathrm{~ms}$ & $285.74 \mathrm{~ms}$ & $6.26 \mathrm{~ms}$ \\
\hline $\mathbf{5 0 0} \mathbf{~ m m}$ & $326 \mathrm{~ms}$ & $326 \mathrm{~ms}$ & $326 \mathrm{~ms}$ & $326.00 \mathrm{~ms}$ & $319.48 \mathrm{~ms}$ & $6.52 \mathrm{~ms}$ \\
\hline $\mathbf{6 0 0} \mathbf{~ m m}$ & $356 \mathrm{~ms}$ & $357 \mathrm{~ms}$ & $356 \mathrm{~ms}$ & $356.33 \mathrm{~ms}$ & $350.00 \mathrm{~ms}$ & $6.33 \mathrm{~ms}$ \\
\hline $\mathbf{7 0 0} \mathbf{~ m m}$ & $384 \mathrm{~ms}$ & $384 \mathrm{~ms}$ & $384 \mathrm{~ms}$ & $384.00 \mathrm{~ms}$ & $378.06 \mathrm{~ms}$ & $5.94 \mathrm{~ms}$ \\
\hline
\end{tabular}




\begin{tabular}{lllllll}
\hline $\mathbf{8 0 0} \mathbf{~ m m}$ & $410 \mathrm{~ms}$ & $411 \mathrm{~ms}$ & $411 \mathrm{~ms}$ & $410.67 \mathrm{~ms}$ & $404.19 \mathrm{~ms}$ & $6.48 \mathrm{~ms}$ \\
\hline $\mathbf{9 0 0} \mathbf{~ m m}$ & $435 \mathrm{~ms}$ & $435 \mathrm{~ms}$ & $434 \mathrm{~ms}$ & $434.67 \mathrm{~ms}$ & $428.73 \mathrm{~ms}$ & $5.94 \mathrm{~ms}$ \\
\hline $\mathbf{1 0 0 0} \mathbf{~ m m}$ & $459 \mathrm{~ms}$ & $458 \mathrm{~ms}$ & $458 \mathrm{~ms}$ & $458.33 \mathrm{~ms}$ & $451.95 \mathrm{~ms}$ & $6.38 \mathrm{~ms}$ \\
\hline $\mathbf{1 1 0 0} \mathbf{~ m m}$ & $480 \mathrm{~ms}$ & $480 \mathrm{~ms}$ & $481 \mathrm{~ms}$ & $480.33 \mathrm{~ms}$ & $474.03 \mathrm{~ms}$ & $6.30 \mathrm{~ms}$ \\
\hline $\mathbf{1 2 0 0} \mathbf{~ m m}$ & $500 \mathrm{~ms}$ & $501 \mathrm{~ms}$ & $501 \mathrm{~ms}$ & $500.67 \mathrm{~ms}$ & $495.14 \mathrm{~ms}$ & $5.53 \mathrm{~ms}$ \\
\hline $\mathbf{1 3 0 0} \mathbf{~ m m}$ & $523 \mathrm{~ms}$ & $524 \mathrm{~ms}$ & $523 \mathrm{~ms}$ & $523.33 \mathrm{~ms}$ & $518.74 \mathrm{~ms}$ & $4.59 \mathrm{~ms}$ \\
\hline
\end{tabular}

In above table, measurement values for different heights are shown. Since three measurements has been made for each height value, these there measurements and mean value of them are shown with theoretical calculation value and error value which is basically difference between mean value and theoretical result. Experiment results show that, maximum error is 6.52 milliseconds at 500 millimeters height, minimum error is 4.59 milliseconds at 1300 millimeters and mean of errors is 5.95 milliseconds. In terms of percentage, maximum error is $3.84 \%$ at 100 millimeters, minimum error is $0.88 \%$ at 1300 millimeters and mean of error percentages is $1.87 \%$.

Error is changing between 4.59 milliseconds and 5.49 milliseconds and variation of the error is similar at each step. Such an error was expected due to the characteristics of electromagnet that used to hold and release the steel ball. Firmware of the device accepts the moment of release as the moment at which voltage of electromagnet is cut. However, due to the electrical characteristics of solenoids, magnetic field applied to the ball by electromagnet is not immediately decreasing to zero. In solenoids, there is a parameter named as time constant which means time for the magnetic field of solenoid to decrease $63 \%$. Required time for the magnetic field to decrease to zero is assumpted as five times of time constant theoretically. Time constant is calculated with below formula [23];

$$
T=\frac{L}{R}
$$

Where $T$ is time constant, $L$ is the inductance of solenoid in units of Henries and $R$ is the resistance value of solenoid between two legs in units of Ohms. Inductance of a solenoid is calculated with below formula [23];

$$
L=\frac{\mu_{0} N^{2} A}{l}
$$

Where $\mu_{0}$ is the vacuum permeability with a standard value of $0.00000125664 \mathrm{H} / \mathrm{m}, N$ is the number of turns of the solenoid, $A$ is the cross sectional area of the solenoid and $l$ is the length of the solenoid. There was not any information about these parameters on the datasheet supplied by the manufacturer of used electromagnet, therefore needed parameters are found by opening the electromagnet and making measurements. Used electromagnet has a number of turns of 550, a resistance of $11.2 \mathrm{Ohms}$, a length of 15 millimeters and a radius of 12 millimeters. Using these parameters and equation (4), inductance of used electromagnet is found as 0.011465 Henries. Using this inductance value and equation (3), time constant of the electromagnet is found as 1.02 milliseconds and required time for the magnetic field to decrease to zero found as 5.1 milliseconds. Steel ball should be starting it's falling motion before magnetic field value completely decreases to zero. However, if this situation is ignored due to the mass of the ball is 28 grams, applied magnetic force according to the manufacturer is 10 kilograms and difference between these two values is very high, 5.1 milliseconds might be considered as the delay created by the electromagnet. If this value is subtracted from masurements at Table 1, below table is obtained.

\begin{tabular}{|c|c|c|c|c|c|c|}
\hline Height & $1^{\text {st }}$ Measurement & $2^{\text {nd }}$ Measurement & $3^{\text {rd }}$ Measurement & Mean & $\begin{array}{c}\text { Theoretical } \\
\text { Value }\end{array}$ & Error \\
\hline $100 \mathrm{~mm}$ & $142.90 \mathrm{~ms}$ & $143.90 \mathrm{~ms}$ & $142.90 \mathrm{~ms}$ & $143.23 \mathrm{~ms}$ & $142.84 \mathrm{~ms}$ & $0.39 \mathrm{~ms}$ \\
\hline $200 \mathrm{~mm}$ & $201.90 \mathrm{~ms}$ & $202.90 \mathrm{~ms}$ & $201.90 \mathrm{~ms}$ & $202.23 \mathrm{~ms}$ & $202.02 \mathrm{~ms}$ & $0.21 \mathrm{~ms}$ \\
\hline $300 \mathrm{~mm}$ & $247.90 \mathrm{~ms}$ & $248.90 \mathrm{~ms}$ & $248.90 \mathrm{~ms}$ & $248.57 \mathrm{~ms}$ & $247.44 \mathrm{~ms}$ & $1.13 \mathrm{~ms}$ \\
\hline $400 \mathrm{~mm}$ & $286.90 \mathrm{~ms}$ & $286.90 \mathrm{~ms}$ & $286.90 \mathrm{~ms}$ & $286.90 \mathrm{~ms}$ & $285.74 \mathrm{~ms}$ & $1.16 \mathrm{~ms}$ \\
\hline $500 \mathrm{~mm}$ & $320.90 \mathrm{~ms}$ & $320.90 \mathrm{~ms}$ & $320.90 \mathrm{~ms}$ & $320.90 \mathrm{~ms}$ & $319.48 \mathrm{~ms}$ & $1.42 \mathrm{~ms}$ \\
\hline $600 \mathrm{~mm}$ & $350.90 \mathrm{~ms}$ & $351.90 \mathrm{~ms}$ & $350.90 \mathrm{~ms}$ & $351.23 \mathrm{~ms}$ & $350.00 \mathrm{~ms}$ & $1.23 \mathrm{~ms}$ \\
\hline $700 \mathrm{~mm}$ & $378.90 \mathrm{~ms}$ & $378.90 \mathrm{~ms}$ & $378.90 \mathrm{~ms}$ & $378.90 \mathrm{~ms}$ & $378.06 \mathrm{~ms}$ & $0.84 \mathrm{~ms}$ \\
\hline 800 mm & $404.90 \mathrm{~ms}$ & $405.90 \mathrm{~ms}$ & $405.90 \mathrm{~ms}$ & $405.57 \mathrm{~ms}$ & $404.19 \mathrm{~ms}$ & $1.38 \mathrm{~ms}$ \\
\hline
\end{tabular}

Table 2. Theoretically corrected measurements with the delay of electromagnet. 


\begin{tabular}{lllllll}
\hline $\mathbf{9 0 0} \mathbf{~ m m}$ & $429.90 \mathrm{~ms}$ & $429.90 \mathrm{~ms}$ & $428.90 \mathrm{~ms}$ & $429.57 \mathrm{~ms}$ & $428.73 \mathrm{~ms}$ & $0.84 \mathrm{~ms}$ \\
\hline $\mathbf{1 0 0 0} \mathbf{~ m m}$ & $453.90 \mathrm{~ms}$ & $452.90 \mathrm{~ms}$ & $452.90 \mathrm{~ms}$ & $453.23 \mathrm{~ms}$ & $451.95 \mathrm{~ms}$ & $1.28 \mathrm{~ms}$ \\
\hline $\mathbf{1 1 0 0} \mathbf{~ m m}$ & $474.90 \mathrm{~ms}$ & $474.90 \mathrm{~ms}$ & $475.90 \mathrm{~ms}$ & $475.23 \mathrm{~ms}$ & $474.03 \mathrm{~ms}$ & $1.20 \mathrm{~ms}$ \\
\hline $\mathbf{1 2 0 0} \mathbf{~ m m}$ & $494.90 \mathrm{~ms}$ & $495.90 \mathrm{~ms}$ & $495.90 \mathrm{~ms}$ & $495.57 \mathrm{~ms}$ & $495.14 \mathrm{~ms}$ & $0.43 \mathrm{~ms}$ \\
\hline $\mathbf{1 3 0 0} \mathbf{~ m m}$ & $517.90 \mathrm{~ms}$ & $518.90 \mathrm{~ms}$ & $517.90 \mathrm{~ms}$ & $518.23 \mathrm{~ms}$ & $518.74 \mathrm{~ms}$ & $0.51 \mathrm{~ms}$
\end{tabular}

This partially theoretical and partially measured correction decreases errors of measurements significally. In this situation, maximum error is 1.42 milliseconds at 500 millimeters height, minimum error is 0.21 milliseconds at 200 millimeters height and mean of errors is 0.85 milliseconds. In terms of precentage, maximum error is $0.46 \%$ at 300 millimeters height, minimum error is $0.09 \%$ at 1200 millimeters height and mean of errors is $0.26 \%$.

Measurement variation is 1 millisecond, in other words at a certain height maximum difference between three measurements is 1 millisecond.

\section{CONCLUSION}

Results show that, designed and implemented mechanism, electronics, embedded firmware and Android application works succesfully to measure fall time of dropped object. Device is ready to be used by students to increase their understanding on free fall topic of physics and to be used by researchers for experiments which do not require more sensitive measurements than 1 millisecond.

Future works may be conducted on this device such as implementing a sensor to exactly obtain the time steel ball escapes from the magnetic field of electromagnet and starts falling. This way, effect of the time constant of electromagnet might be observed experimentally and the error of raw measurements might be decreased. Furthermore, a sensor may be implemented in order to measure drop velocity of the ball, with this implementation velocity and time measurements can be compared.

In addition, it is planned to add control over internet with real-time display feature to the device in order to make it possible to make experiments far from the device. Also, computer control can be added to the device, although Android mobile control is the novelty of this study, computer control option with it may increase the usefulness.

Although there are some errors both on raw and corrected measurements, since these errors are not very high, device can be used in educational and experimental processes about free fall.

\section{ACKNOWLEDGMENTS}

I would like to thank my all isnstructors at Yıldırım Beyazit University Electrical and Electronics Engineering Department.

\section{CONFLICT OF INTEREST}

The authors declare that there is no conflict of interest regarding the publication of the paper.

\section{REFERENCES}

[1] A. Abdi, The effect of inquiry-based learning method on students' academic achievement in science course. Universal Journal of Educational Research, 2:1 (2014) 37-41.

[2] D. Conrad, D. Hedin, The impact of experimental education on adolescent development. Child \& Youth Services, 4:3-4 (1982) 57-76.

[3] A. Ferreira, A. S. Seyffert, M. Lemmer, Developing a graphical tool for students to understand air resistance and free fall: when heavier objects do fall faster. Physics Education, 52:3 (2017) 34-36.

[4] C. Chiaverina, M. Vollmer, Learning physics from experiments. Informal Learning and Public Understanding of Physics: Third International GIREP Seminar. (2005). 
[5] M. Stefanovic, D. Tadic, S. Nestic, A. Djordjevic, An assessment of distance learning laboratory objectives for control engineering education. Computer Applications in Engineering Education, 23:2 (2013) 191-202.

[6] B. Çatalbaş, İ. Uyanık, A low-cost laboratory experiment setup for frequency domain analysis for a feedback control systems course. IFAC-PapersOnLine, 50:1 (2017) 15704-15709.

[7] J. Cavalcanti, L. F. C. Figueredo, J. Y. Ishihara, M. C. Bernardes, P. H. R. Q. A. Santana, A. N. Vargas, G. A. Borges, A real-time web-based networked control system education platform. The International Journal of Electrical Engineering \& Education, 55:2 (2018) 130-141.

[8] H. Vargas, J. Sanchez, N. Duro, R. Dormido, S. Dormido-Canto, G. Farias, S. Dormido, A systematic two-layer approach to develop web-based experimentation environments for control engineering education. Intelligent Automation and Soft Computing, 14:4 (2008) 505-524.

[9] M. Kaluz, L. Cirka, R. Valo, M. Fikar, ArPi Lab: A low-cost remote laboratory for control education. IFAC Proceedings Volumes, 47:3 (2014) 9057-9062.

[10] Ş. Demirbaş, İnternet tabanlı PI kontrollü bir doğru akım motoru deney seti. Journal of the Faculty of Engineering and Architecture of Gazi University, 22:2 (2007) 401-410.

[11] S. Kaçar, A. F. Arıcıŏlu, H. Tekin, PID denetleyici uygulamaları için yeni bir online deney seti tasarımı. Sakarya University Journal of Science, 21:1 (2017) 34-46.

[12] M. Z. Stefanovic, M. Matijevic, Remote controlled laboratory experiments on the web. The International Journal of Industrial Engineering, 18:3 (2011) 130-139.

[13] A. Calpbinici, Elektrik makinaları deney setlerine eşzamanlı erişim sağlayabilen bir e-laboratuvar tasarımı. Gazi University Master Thesis, (2014).

[14] F. Barrero, S. Toral, S. Gallardo, eDSPLab: remote laboratory for experiments on DSP applications. Internet Research, 18:1 (2008) 79-92.

[15] S. Taşkın, M. Demetgül, Bir sıvı dolum tesisi deney setinin uzaktan kontrolü. Journal of Polytechnic, 12:1 (2009) 35-41.

[16] G. Mutlu, Uzaktan erişimli güç elektroniği laboratuvarı. Gazi University Master Thesis, (2012).

[17] R. Gülcan, Uzakran kontrollü ARM tabanlı mikrodenetleyici denet seti tasarımı ve gerçekleştirilmesi. Akdeniz University Master Thesis, (2019).

[18] R. Günaydın, Uzaktan erişimli web tabanlı mikrodenetleyici deney seti tasarımı ve gerçekleştirilmesi. Karabük University Master Thesis, (2014).

[19] B. Subali, D. Rusdiana, H. Firman, I. Kaniawati, E. Ellianawati, Computer-based experiment of free fall movement to improve the graphical literacy. Indonesian Journal of Science Education, 6:1, (2017), 41-48.

[20] D. Akgün, İ. Çankaya, Bilgisayar kontrollü serbest düşme deney sisteminin tasarımı. Sakarya University Journal of Science, 7:2, (2003) 31-36.

[21] A. A. Süzen, K. Kayaalp, Free fall test system controlled by computer with Arduino. Journal of Engineering Sciences and Design, 7:4 (2019) 878-884.

[22] P. Vogt, J. Kuhn, Analyzing free fall with a smartphone acceleration sensor. The Physics Teacher, 50:3 (2012) 182-183.

[23] J. Walker, D. Halliday, R. Resnick, Fundamentals of Pyhsics (8. Edition Extended), John Wiley \& Sons, Hoboken, 2008. 